J. Lake Sci. (湖泊科学), 2014, 26(2):253-259

http: //www. jlakes. org. E-mail : jlakes@niglas.ac.cn

(c) 2014 by Journal of Lake Sciences

\title{
鄱阳湖国家级自然保护区湿地植被的干旱响应及影响因素”
}

\author{
叶 春 $^{1,2}$, 吴桂平 ${ }^{1}$,赵晓松 ${ }^{1}$, 王晓龙 ${ }^{1}$, 刘元波 $^{1 * *}$ \\ (1:中国科学院南京地理与湖泊研究所,南京 210008) \\ (2:中国科学院大学,北京 100049)
}

\begin{abstract}
摘 要: 近年来鄱阳湖干旱事件频发,干旱导致的气象水文要素变化直接影响植被生长状况,尤其是对于地上植被生物 量的影响极为显著. 研究鄱阳湖干旱事件对于湿地植被的影响, 对于保护鸟类栖息地,认识湿地生态功能和结构的变化 具有重要的现实意义. 利用长期卫星遥感数据, 结合植被生物量野外调查, 以 2003 和 2006 年极端干旱年份为出发点, 从 湿地植被面积、生物量密度和总生物量的角度分析了鄱阳湖湿地植被生物量对于极端干旱的响应. 研究表明: 湿地植被 面积、生物量密度以及总生物量均呈现双峰分布特征, 在 4 和 11 月分别达到上、下半年的峰值. 2003 年植被生物量与多 年均值一致,2006 年下半年植被面积、生物量密度以及总生物量均明显超出多年均值. 影响湿地植被面积的主要因素为 鄱阳湖水位变化; 而影响植被生物量密度的主要因素为气温和水位,退水时间提前对于生物量密度影响最大; 总生物量 同时受到植被面积与植被生物量密度的综合影响,其中植被面积的影响更大,植被面积对于总生物量的影响在 2006 年表 现得比 2003 年更加显著. 总之,2006 年湿地植被对水文干旱的响应要比气象干旱强烈得多.
\end{abstract}

关键词: 鄱阳湖;干旱;总生物量;植被面积;生物量密度;遥感

\section{Responses of wetland vegetation to droughts and its impact factors in Poyang Lake National Nature Reserve}

\author{
YE Chun $^{1,2}$, WU Guiping ${ }^{1}$, ZHAO Xiaosong ${ }^{1}$, WANG Xiaolong ${ }^{1}$ \& LIU Yuanbo ${ }^{1}$ \\ (1: Nanjing Institute of Geography and Limnology, Chinese Academy of Sciences, Nanjing 210008, P. R. China) \\ (2: University of Chinese Academy of Sciences, Beijing 100049, P. R. China)
}

\begin{abstract}
Recent droughts have changed meteorological and hydrological conditions of Lake Poyang and caused great influences on vegetation growth, especially for the vegetation biomass on the ground. To investigate the influences of droughts on vegetation, it is vital to preserve habitats for migrating birds and to understand the ecological functionality of wetland. For this purpose, we used long-term satellite data to inspect the response of vegetation biomass associated with field measured vegetation biomass for the typical drought years 2003 and 2006 in terms of vegetation area, biomass density and total biomass. Vegetation area, biomass density and total biomass show general two peaks across 2003 and 2006, and the peaks occur in April and November, respectively. The biomass had little variation by comparison with multi-year mean biomass between 2001 and 2010 , while biomass for the second half year of 2006 are much higher than multi-year averages for corresponding months. The dominating factor affecting vegetation area is the lake water level, while biomass density is affected by temperature. The time of water recession has the greatest influence on biomass density variations. The total biomass is affected by both vegetation area and biomass density, and the magnitude of effects of vegetation area is more than that of biomass density. This is more significant for 2006 than 2003 . To conclude, response of vegetation to hydrological drought is much stronger than that to meteorological drought in 2006.
\end{abstract}

Keywords: Lake Poyang; drought; total biomass; vegetation area; biomass density; remote sensing

* 国家重点基础研究发展计划“973”项目 (2012CB417003) 和中国科学院南京地理与湖泊研究所“一三五”战略发展 重点项目 (NIGLAS2012135001) 联合资助. 2013-05-02 收稿;2013-06-28 收修改稿. 叶春 (1981 ) , 男, 博士 研究生; E-mail:echoyc@163.com.

** 通信作者;E-mail:ybliu@ niglas. ac. cn. 
湿地被誉为“地球之肾”, 是连接水陆最为重要的生态系统之一. 湿地植被生物量是评价生态系统功能 的重要指标之一 ${ }^{[1]}$. 作为我国最大的淡水湖泊, 鄱阳湖 “高水似湖, 低水似河” 的独特水情变化为湿地生物多 样性提供了良好的天然条件 ${ }^{[2]}$. 鄱阳湖湿地植被受到水文过程影响, 存在着年内波动和年际波动两种形式, 在空间分布上也表现出明显的水分梯度 ${ }^{[3-6]}$. 近年来鄱阳湖地区极端干旱事件频发, 引起国内外的广泛关 注 $^{[7-11]}$. 气象水文要素的变化过程直接影响植被的生长, 尤其是地上生物量, 进而影响鸟类栖息地环境以及 湖区生态系统的结构和功能. 研究干旱对湖区植被生物量的影响, 对于深人地认识湿地生态系统结构和功 能变化以及更好地保护珍稀鸟类等具有重要的现实意义.

卫星遥感技术具有宏观、连续、长期的对地监测能力, 在湖泊湿地研究中发挥着越来越重要的作 用 ${ }^{[12-16]}$, 为深人揭示湿地植被对环境变化的宏观响应奠定了良好的基础. 本文以鄱阳湖国家自然保护区为 研究区域, 利用长期遥感数据, 结合植被生物量野外调查, 通过建立植被生物量与遥感指数之间的关系模 型, 根据湖区降水以及水位数据变化特征, 选取 2003 和 2006 年作为典型气象干旱与水文干旱代表年 ${ }^{[17]}$, 剖 析湖区湿地植被生物量对极端干旱的响应,并探讨环境要素对湿地植被的影响.

\section{1 研究区及数据来源}

\section{1 研究区概况}

鄱阳湖国家自然保护区 $\left(29^{\circ} 05^{\prime} \sim 29^{\circ} 15^{\prime} \mathrm{N}, 115^{\circ} 55^{\prime} \sim 116^{\circ} 03^{\prime} \mathrm{E}\right)$ 位于鄱阳湖西北角, 赣江北支和修水的 交汇处 (图 1). 该保护区以永修县吴城镇为中心, 下辖 9 个子湖泊及其草洲, 总面积 $331 \mathrm{~km}^{2}$, 属亚热带湿润 季风型气候区, 年均气温 $17.8^{\circ} \mathrm{C}$, 多年平均降水量 $1450 \sim 1550 \mathrm{~mm}^{[2]}$. 鄱阳湖水位一般自 4 月开始上涨, 7 月 达到全年峰值, 9 月至次年 1 月下降, 洲滩出露 ${ }^{[2]}$. 湖区 $16 \mathrm{~m}$ 以上高程带的植被以芦苇和南荻群落为主, $14 \sim$ $16 \mathrm{~m}$ 高程带的植被以苔草群落为主, $14 \mathrm{~m}$ 以下高程带洲滩出露时湿地植被以苔草、虉草群落为主 ${ }^{[18-19]}$.

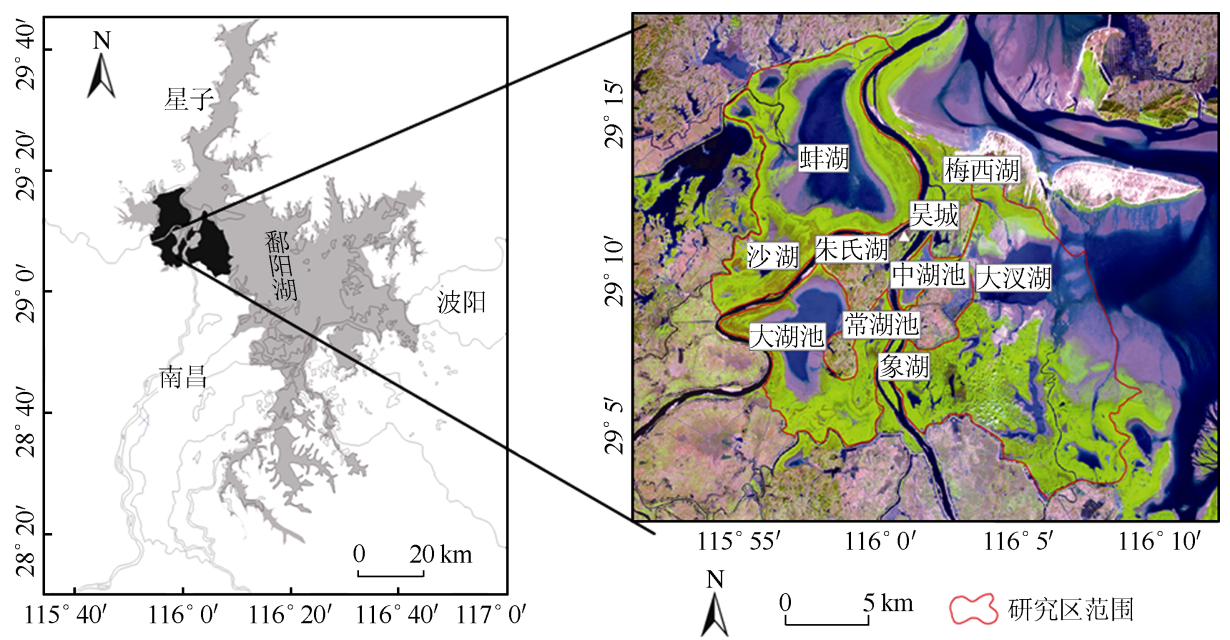

图 1 研究区地理位置

Fig. 1 Geographical location of study area

\section{2 数据资料}

1.2 .1 生物量密度调查 选择研究区内地形相对平坦的出露洲滩, 于 2008-2010 年 9-11 月对研究区进行 每半月一次的植被采样. 每个样点采集 $1 \mathrm{~m} \times 1 \mathrm{~m}$ 样方 3 个, 记录采样点各样方内植被类型以及经纬度坐标, 测量刈割后的植被鲜重,样点内各样方测量均值表示该样点的地上植被生物量.

1.2.2 遥感数据及预处理 遥感数据来自 NASA MODIS 植被指数产品 (MOD13Q1), 数据格式为 EOS-HDF, 空间分辨率为 $250 \mathrm{~m}$, 时间分辨率为 $16 \mathrm{~d}$, 每年共有 23 景影像 ( http:// reverb. echo. nasa. gov/). 2001-2010 
年, 共计 230 景影像. 由于研究区处于湿润区, 光学遥感影像常受到云的影响, $16 \mathrm{~d}$ 合成数据仍然有较多噪 音, 而湿地区域的植被受到周期性或非周期性的水文影响, 波动非常大, 常用的时间序列去噪方法在湿地应 用较为困难 ${ }^{[20]}$, 因此本文采用线性插值方法, 在保留其较高空间分辨率的同时, 通过 $16 \mathrm{~d}$ 合成数据转换为 月值, 进一步去除噪音 ${ }^{[21]}$. 从影像中提取 $E V I$ ( enhanced vegetation index) 数据, 利用公式 (1) 转换成月值:

$$
E V I_{\text {monthly }, j}=a_{j} \cdot \operatorname{EVI}(i)+b_{j} \cdot \operatorname{EVI}(i+16)+c_{j} \cdot E V I(i+32)
$$

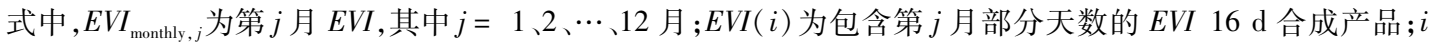
为每 $16 \mathrm{~d}$ 产品编号, $i=001 、 017 、 \cdots 、 337 、 353 ; a 、 b 、 c$ 为所涉及月份所占该月的比例. 利用湖区矢量边界, 切 割得到研究区范围内的 $E V I$ 影像系列.

1.2 .3 气象、水文与 DEM 高程数据 选取南昌和波阳两个气象站以及星子水文站, 获取 1960-2010 年湖区 逐日气温、降水和水位数据, 其中气温与降水数据为南昌、波阳两站点的平均值. DEM 高程数据为来自江西 省水文局的 1980 年鄱阳湖湖盆实测数据.

\section{2 研究方法}

\section{1 湿地植被的分布面积提取与总生物量估算}

研究区植被生物量特征可用植被分布面积、生物量密度和总生物量来表示. 基于植被的红波段吸收特 征和近红外波段强反射特征, 利用 $E V I$ 阈值法, 有效地提取植被分布图. 根据实地测量植被生物量与同期 $E V I$ 之间存在的显著性幂指数关系 ${ }^{[22]}$, 计算研究区生物量密度, 即:

$$
\text { BIOMASS }=5184.7 E V I^{1.271}\left(R^{2}=0.823\right)
$$

式中, BIOMASS 为植被生物量密度 $\left(\mathrm{g} / \mathrm{m}^{2}\right)$. 进一步结合植被分布, 计算得到 2001-2010 年逐月湿地植被总 生物量.

\section{2 湿地植被干旱响应的影响因素}

湿地植被对干旱的宏观响应主要体现在植被面积、生物量密度和总生物量的变化. 就环境要素而言, 研 究区的植被面积变化取决于湖泊水位变化, 生物量密度取决于降水和气温等水热条件, 而总生物量变化则 取决于植被面积和生物量密度两方面因素. 使用数理统计方法, 获得环境因素 (气温、降水以及水位) 与植被 生物量密度之间以及植被面积之间的相关关系,进而剖析极端干旱对湿地生物量的影响.

植被总生物量变化与植被面积和生物量密度有关. 植被面积和生物量密度对总生物量变化的贡献可表 示为:

$$
\begin{aligned}
\Delta T_{\mathrm{A}} & =\Delta A \cdot B_{\text {mean }} \\
\Delta T_{\mathrm{B}} & =\Delta B \cdot A_{\text {mean }}
\end{aligned}
$$

式中, 植被分布面积与生物量密度所引起的总生物量距平分量分别记为 $\Delta T_{\mathrm{A}}$ 和 $\Delta T_{\mathrm{B}}$, 单位为 $\mathrm{kg} ; \Delta A$ 为某一 时期植被分布面积与同期多年平均植被面积之差 $\left(\mathrm{m}^{2}\right) ; \Delta B$ 为某一时期生物量密度与同期多年平均生物量 密度之差 $\left(\mathrm{g} / \mathrm{m}^{2}\right) ; B_{\text {mean }}$ 与 $A_{\text {mean }}$ 分别为某个月份多年平均植被面积 $\left(\mathrm{m}^{2}\right)$ 和生物量密度 $\left(\mathrm{g} / \mathrm{m}^{2}\right)$.

\section{3 结果与分析}

\section{1 水文气象要素变化特征}

就多年平均而言, 鄱阳湖区降水主要集中在 4-6 月份, 下半年降水较少. 2003 年上半年降水量超过同 期多年 (1960-2010 年) 月均降水量, 下半年逐月降水量低于多年逐月均值, 7-10 月份分别减少了 $80 \mathrm{~mm}$ $(41 \%) 、 82 \mathrm{~mm}(32 \%) 、 35 \mathrm{~mm}(47 \%)$ 和 $32 \mathrm{~mm}(39 \%) .2006$ 年上半年降水量与多年月均降水量持平, 下半 年降水量低于多年月均降水量, 7-10 月分别减少 58\%、52\%、53\% 和 59\% (图 2a). 可以看出, 2003 年和 2006 年下半年降水大约只占常年同期降水的一半, 表明下半年气象干旱十分明显, 而 2006 年降水亏缺更为 严重. 
从鄱阳湖区气温来看, 多年平均气温为 $17.8^{\circ} \mathrm{C}$, 呈现单峰分布, 冬季最低, 7 月最高. 2003 年 7、8 和 9 月 气温分别达到 $31.8 、 30.4$ 和 $26.8^{\circ} \mathrm{C}$, 超过多年月均气温 $2.2 、 1.3$ 和 $1.7^{\circ} \mathrm{C} .2006$ 年下半年, 除 9 月气温略低 于多年月均气温 $0.6^{\circ} \mathrm{C}, 7$ 和 8 月分别高出 0.7 和 $1.2^{\circ} \mathrm{C}$, 但低于 2003 年同期水平 (图 $2 \mathrm{a}$ ). 在不限制植被生 长的条件下, 温度升高预示着湖区蒸散加大, 加剧了下半年的气象干旱程度, 2003 年比 2006 年更为 强烈 ${ }^{[17]}$.

鄱阳湖区多年平均水位在 $8 \sim 18 \mathrm{~m}$ 之间, 呈现单峰分布, 2 月最低, 7 月最高. 与多年平均水位相比, 2003 年上半年水位偏高 $(9.64 \% \pm 10.3 \%)$,下半年基本持平. 2006 年上半年水位基本持平,下半年出现显著降 低, 7-11 月均低于同期多年平均水位 $2 \mathrm{~m}$ 以上 (图 2b). 以上分析表明,2003 和 2006 年下半年都出现了严 重的气象干旱, 而 2006 年下半年还同时出现了严重的水文干旱.
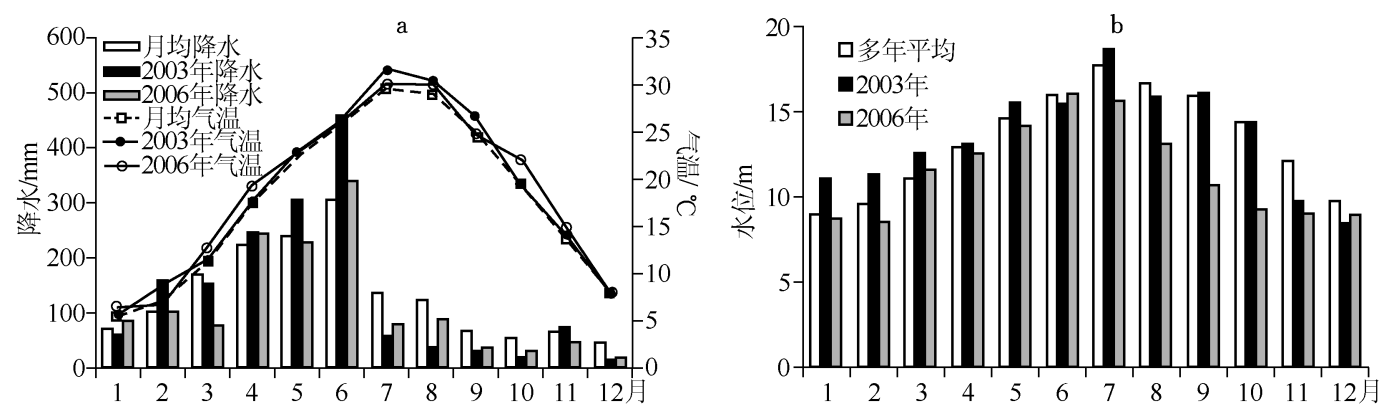

图 2 鄱阳湖国家级自然保护区 2003 年和 2006 年及多年 (1960- 2010 年) 降水量、气温 (a)及水位 (b) 逐月变化

Fig. 2 Monthly variations of precipitation, temperature(a) and lake water level(b) for 2003 , 2006 and 1960 - 2010 multi-year average in Poyang Lake National Nature Reserve

\section{2 植被生物量变化特征}

从多年平均情况来看, 湿地植被面积自 1 月缓慢增加, 4 月份达到上半年的最大值, 此后植被面积逐月 减少, 7 月达到最小值,下半年植被面积在 11 月达到最大值. 相对于多年均值而言, 2003 年 7 月份植被面积 仅为 $17 \mathrm{~km}^{2}$, 低于多年平均值 $82.1 \%$; 其他月份与多年平均值相差不大 $(-2.47 \% \pm 11.36 \%) .2006$ 年上半 年植被面积接近多年平均值 $(-6.50 \% \pm 10.1 \%)$; 7 月以后, 植被面积超出多年均值 $51 \%$ 以上, 尤其是 $8 、 9$ 和 10 月分别超出多年平均值的 $112.4 \% 、 105.7 \%$ 和 $42.3 \% ; 11-12$ 月植被面积仍略高于多年均值 (图 3a). 这些情况表明,尽管 2003 和 2006 年都发生了极端干旱事件,但植被分布面积变化却截然不同, 2003 年下半 年除 7 月外,其他月份的植被面积接近多年平均水平,而 2006 年下半年远高于多年平均状况.

就多年平均而言, 湿地植被生物量密度呈现双峰分布, 峰值分别出现在 4 和 11 月. 4 月生物量密度峰值 比 11 月高出大约 $33 \%$, 表明春季湿地植被较秋季旺盛. 对比多年平均状况, 2003 年生物量密度变化与多年 平均值较为接近, 平均差异 $2.84 \% \pm 15.2 \%$. 而 2006 年上半年接近多年平均状况, 下半年则显著高于多年 平均状况, 9 月提前达到峰值, 并接近于春季多年平均水平 (图 3b). 由此可见, 这两个年份生物量密度与植 被面积变化类似: 上半年与多年平均情况接近, 2003 年下半年与多年平均状况接近,而 2006 年下半年则明 显高于多年平均水平.

就多年平均而言, 植被总生物量与植被生物量密度变化相似, 同样呈现双峰分布, 分别出现在 4 和 11 月,而 4 月高于 11 月. 最低值出现在 7 月份. 相对于多年平均而言, 2003 年与多年平均情况较为接近 $(-9.33 \% \pm 30.9 \%) .2006$ 年上半年总生物量整体略低于多年均值 $(-9.0 \% \pm 20.4 \%)$, 而下半年显著超 出多年均值, 9 和 10 月分别超出同期多年均值的 190\% 和 61\%. 整体而言, 2003 年总生物量与多年平均水平 一致, 2006 年上半年总生物量低于同期多年均值, 下半年总生物量显著增加, 并在 9 月提前达到最大值 (图 3c). 由此可见, 2003 年与 2006 年在湿地植被面积、生物量密度与总生物量上, 既存在相似之处, 又存在差异 性, 需要从环境因素变化角度来阐释.

\section{3 湿地植被干旱响应的影响因素}

3.3.1 植被面积的影响因素 由于湖区植被地处亚热带湿润气候区, 降水和温度等水热条件并非植被分布 
的限制性因素. 影响陆地植被分布的主要限制性因 素是洲滩是否出露,即是否退水 (水位). 图 4 给出 了 2003 和 2006 年下半年进人干旱时期,植被面积 与水位之间的统计关系. 总体而言, 植被面积与湖 泊水位存在显著的负相关关系 $(P<0.05)$,植被面 积随着水位的升高而缩小,水位每升高 $1 \mathrm{~m}$,植被面 积降低约 $16 \sim 19 \mathrm{~km}^{2}$. 另一方面,2006 年植被面积 总体高于 2003 年, 尤其是 7、8、9 和 10 月分别高出 $114 、 114 、 125$ 和 $131 \mathrm{~km}^{2}$. 即使在同等水位条件下, 2006 年植被面积也略高于 2003 年 (图 4), 这可能 与 2006 年洲滩出露过早有关, 越早出露的洲滩, 植 被的生长期越长.

3.3 .2 植被生物量密度的影响因素在洲滩出露 之后, 植被的生长在不同程度上受到水热条件的影 响, 主要体现在气温和降水量等. 统计分析表明, 植 被生物量密度与降水量不存在显著相关关系 $(P>$ $0.05)$, 主要原因在于研究区气候湿润, 土壤水充 足, 即使降水减少亦足够支撑植被生长的需要. 冯 妍等和郑有飞等对植被生长与气象要素的分析表 明, 相对于降水而言, 气温对于湿润区植被生长更 为重要 ${ }^{[23-24]} .2003$ 年下半年湿地植被生物量密度 与气温的相关关系显著 $(P<0.05)$, 而 2006 年并不 显著(图 5a)。

值得注意的是, 2003 年下半年生物量密度与 水位的统计关系更为密切 (图 5b). 水位并不直接 影响湿地植被长势, 但水情变化影响洲滩出露早 晚, 进而影响湿地植被生长期的长短和植被的生物 量水平 ${ }^{[4]} .2003$ 年下半年尽管气温偏高, 但退水没 有提前,生物量密度并无显著改变; 而 2006 年则由 于退水提前, 植被生长初期的气温有利于植被迅速 生长, 9 月即提前达到最大值. 综上所述, 影响植被 生物量密度的主要因素并非降水, 而是气温和水 位, 退水时间提前对生物量密度的影响更大. 因此, 以低水位为特征的水文干旱对植被生物量密度的 影响比以降水亏缺为特征的气象干旱更大.

3.3.3 植被总生物量的影响因素植被总生物量 的变化是植被面积与生物量密度双重影响的结果. 相对于多年平均水平, 2003 年鄱阳湖自然保护区湿 地植被总生物量月均值减少 $0.97 \times 10^{7} \mathrm{~kg}$, 而 2006 年则增加 $8.9 \times 10^{7} \mathrm{~kg} .2003$ 年由于植被生物量密度 变化,引起总生物量总体减少了 $3 \%$, 而植被面积改 变则导致总生物量总体减少 $13 \%$, 普遍高于植被生 物量密度引起的变化. 2006 年与 2003 年类似, 由于 生物量密度变化导致总生物量总体增加了 $13 \%$, 而
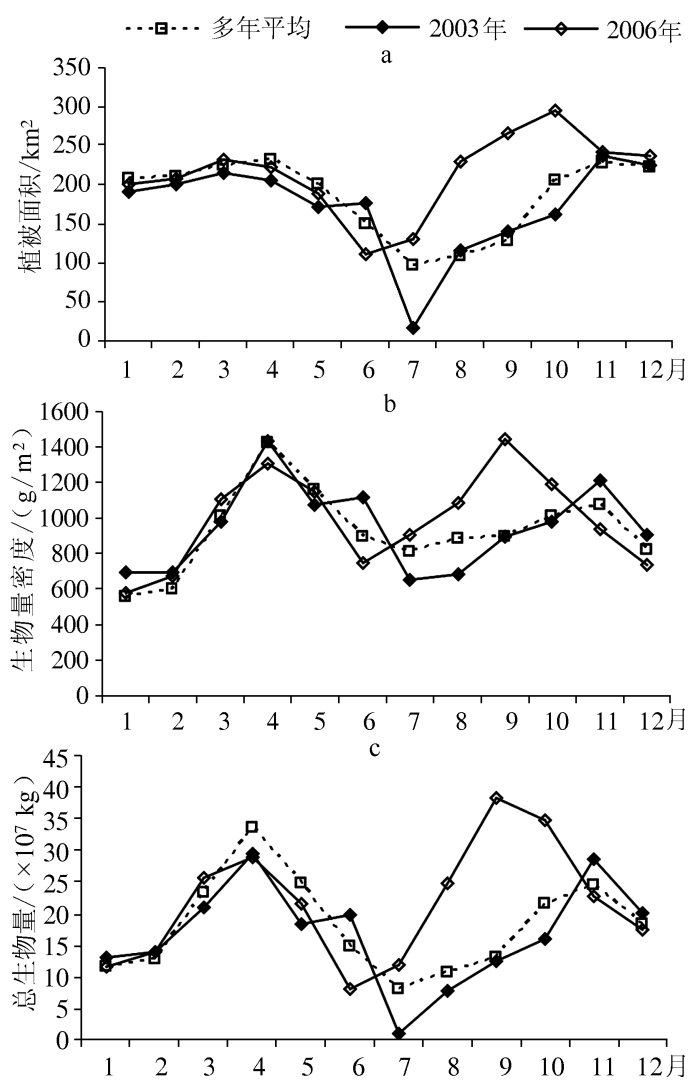

图 3 鄱阳湖国家级自然保护区 2003 年和 2006 年及 多年 $(2001-2010$ 年)平均植被面积 (a)、 生物量密度 $(\mathrm{b})$ 和总生物量 $(\mathrm{c})$ 逐月变化

Fig. 3 Monthly variations of vegetation area(a), biomass density ( b ) and total biomass (c) for 2003, 2006 and 2001-2010 multi-year average in Poyang Lake National Nature Reserve

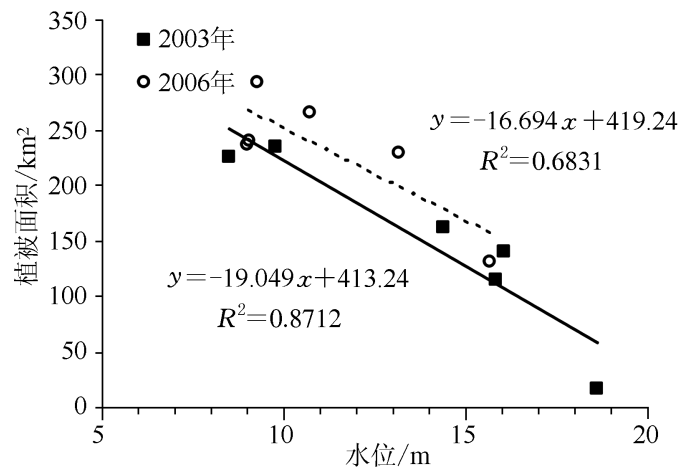

图 4 鄱阳湖国家级自然保护区 2003 和 2006 年下半年 湿地植被面积与湖泊水位之间的关系

Fig. 4 Statistical relationship between vegetated area and lake water level for the second half-year of 2003 and 2006 in Poyang Lake National Nature Reserve 

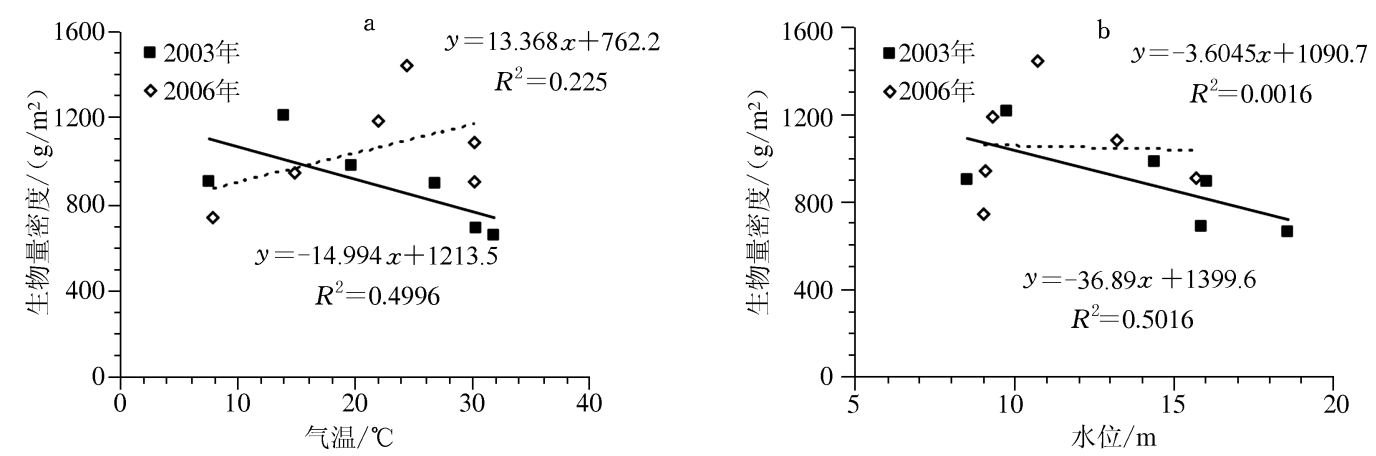

图5 鄱阳湖国家级自然保护区 2003 和 2006 年下半年湿地植被生物量密度与气温 (a)、湖泊水位 (b) 的关系

Fig. 5 Statistical relationship between vegetated area and air temperature(a) and lake water level(b) for the second half-year of 2003 and 2006 in Poyang Lake National Nature Reserve

植被面积变化则导致总生物量总体升高了 46\% (表 1). 由于植被面积变化主要取决于水位变化, 而生物量 密度既与气温有关, 又与退水早晚有关, 因此水位变化与退水早晚对总生物量的影响最大, 其次才是气温. 在这个意义上,研究区总生物量变化对水文干旱的响应比气象干旱要强烈得多.

表 1 鄱阳湖国家级自然保护区 2003 与 2006 年下半年湿地植被的总生物量逐月变化以及 生物量密度和植被面积的贡献

Tab. 1 Variations of total biomass and contributions from biomass density and vegetation area in the second half-year of 2003 and 2006 in Poyang Lake National Nature Reserve

\begin{tabular}{|c|c|c|c|c|c|c|c|c|c|c|c|c|c|}
\hline \multirow[b]{2}{*}{ 月份 } & \multirow[b]{2}{*}{$\begin{array}{c}\text { 总生物 } \\
\text { 量多年 } \\
\text { 均值/ } \\
\left(\times 10^{7}\right. \\
\mathrm{kg})\end{array}$} & \multicolumn{6}{|c|}{2003 年 } & \multicolumn{6}{|c|}{2006 年 } \\
\hline & & $\begin{array}{c}\text { 总生物 } \\
\text { 量距平/ } \\
\left(\times 10^{7}\right. \\
\mathrm{kg})\end{array}$ & 百分比 & $\begin{array}{c}\text { 密度距 } \\
\text { 平贡献 } \\
\left(\times 10^{7}\right. \\
\mathrm{kg})\end{array}$ & 百分比 & $\begin{array}{c}\text { 面积距 } \\
\text { 平贡献/ } \\
\left(\times 10^{7}\right. \\
\mathrm{kg})\end{array}$ & 百分比 & $\begin{array}{c}\text { 总生物 } \\
\text { 量距平/ } \\
\left(\times 10^{7}\right. \\
\mathrm{kg})\end{array}$ & 百分比 & $\begin{array}{c}\text { 密度距 } \\
\text { 平贡献/ } \\
\left(\times 10^{7}\right. \\
\mathrm{kg})\end{array}$ & 百分比 & $\begin{array}{c}\text { 面积距 } \\
\text { 平贡献/ } \\
\left(\times 10^{7}\right. \\
\mathrm{kg})\end{array}$ & 百分比 \\
\hline 7 & 8.3 & -6.6 & $-80 \%$ & -1.4 & $-17 \%$ & -6.3 & $-77 \%$ & 3.6 & $43 \%$ & 0.9 & $11 \%$ & 2.8 & $34 \%$ \\
\hline 8 & 10.9 & -1.6 & $-15 \%$ & -2.1 & $-20 \%$ & 0.6 & $6 \%$ & 14.0 & $129 \%$ & 2.2 & $20 \%$ & 10.7 & $99 \%$ \\
\hline 9 & 13.2 & 1.0 & $8 \%$ & 0 & 0 & 1.0 & $7 \%$ & 25.1 & $190 \%$ & 7.2 & $54 \%$ & 12.1 & $92 \%$ \\
\hline 10 & 21.6 & -4.8 & $-22 \%$ & -0.6 & $-3 \%$ & -4.4 & $-20 \%$ & 13.2 & $61 \%$ & 3.7 & $17 \%$ & 8.8 & $41 \%$ \\
\hline 11 & 24.5 & 4.2 & $17 \%$ & 3.2 & $13 \%$ & 0.9 & $4 \%$ & -1.8 & $-7 \%$ & -2.9 & $-12 \%$ & 1.5 & $6 \%$ \\
\hline 12 & 18.3 & 2.0 & $11 \%$ & 1.8 & $10 \%$ & 0.2 & $1 \%$ & -0.7 & $-4 \%$ & -1.8 & $-10 \%$ & 1.2 & $6 \%$ \\
\hline
\end{tabular}

\section{4 结论}

1) 湿地植被面积、生物量密度以及总生物量年内变化均呈现双峰特征. 2003 年植被生物量逐月变化与 多年平均水平相一致. 而 2006 年下半年, 无论是植被面积、生物量密度还是总生物量, 均明显超出多年平均 水平.

2) 影响植被生物量密度的主要因素为气温和水位, 而退水时间提前对生物量密度的影响更大. 以低水 位为特征的 2006 年水文干旱对植被生物量密度的影响, 比以降水亏缺为特征的气象干旱更大.

3 ) 植被面积对总生物量的影响总体上大于生物量密度,2006 年比 2003 年表现得更为明显. 水位与退 水时间对生物量的影响最大, 其次是气温. 因此, 总生物量对 2006 年水文干旱的响应比 2003 年气象干旱要 强烈得多.

致谢: 感谢中国科学院南京地理与湖泊研究所鄱阳湖湿地观测研究站在野外工作中的相关支持, 中国科学 院南京地理与湖泊研究所孙占东副研究员提供水文数据. 


\section{5 参考文献}

[1 ] 李 爽, 张祖陆, 周德民. 湿地植被地上生物量遥感估算模型研究一以洪河湿地自然保护区为例. 地理研究, $2011, \mathbf{3 0}(2): 278-290$.

[ 2 ] 朱海虹, 张 本. 鄱阳湖一一水文、生物、沉积、湿地、开发整治. 合肥: 中国科学技术大学出版社, 1997:203.

[ 3 ] 吴 琴,尧 波,朱丽丽等. 鄱阳湖典型苔草湿地生物量季节变化及固碳功能评价. 长江流域资源与环境,2012, 21 (2) :215-219.

[4] 叶 春,刘元波,赵晓松等. 基于 MODIS 的鄱阳湖湿地植被变化及其对水位的响应研究. 长江流域资源与环境, 2013, 22(6) : 707-714.

[ 5 ] 张方方,齐述华, 廖富强等. 鄱阳湖湿地出露草洲分布特征的遥感研究. 长江流域资源与环境, 2011, 20(11)： 1361-1367.

[ 6 ] 周文斌,万金保,姜加虎等. 鄱阳湖江湖水位变化对其生态系统影响. 北京:科学出版社,2011:79.

[ 7 ] 闵 骞. 鄱阳湖区干旱的定量判别与变化特征. 水资源研究,2007,28(1):5-7.

[8] 闵 骞,闵 聑. 鄱阳湖区干旱演变特征与水文防旱对策. 水文,2010,30(1):84-88.

[ 9 ] 胡振鹏, 葛 刚,刘成林等. 鄱阳湖湿地植物生态系统结构及湖水位对其影响研究. 长江流域资源与环境,2010,19 (6) : 597-605.

[10］甘小艳,刘成林,黄小敏. 鄱阳湖干旱分析. 安徽农业科学,2011,39(24):14676-14678.

[11] Feng L, Hu CM, Chen XL. Satellites capture the drought severity around China's largest freshwater lake. IEEE Journal of Selected Topics in Applied Earth Observations and Remote Sensing, 2012, 5(4) :1266-1271.

[12] Ozesmi SL, Bauer ME. Satellite remote sensing of wetlands. Wetlands Ecology and Management, 2002,10 (5):381-402.

[13] Silva TSF, Costa MPF, Melack JM. Spatial and temporal variability of macrophyte cover and productivity in the eastern Amazon floodplain: A remote sensing approach. Remote Sensing of Environment, 2010,114(9) : 1998-2010.

[14] Arieira J, Karssenberg D, Jong SM et al. Integrating field sampling, spatial statistics and remote sensing to map wetland vegetation in the Pantanal, Brazil. Biogeosciences, 2011, 8:667-686.

[15］陈水森,詹志明. 基于 GIS 的鄱阳湖湿地遥感调查实验研究. 热带地理, 1999,19(1):35-38.

[16］雷 声,张秀平, 许小华. 鄱阳湖湿地植被秋冬季变化多源遥感监测分析. 人民长江, 2011, 42(11):60-64.

[17] 刘元波,张 奇,刘 健等. 鄱阳湖流域气候水文过程及水环境效应. 北京:科学出版社,2012:211.

[18］吴建东,刘观华,金 杰等. 鄱阳湖秋季洲滩植物种类结构分析. 江西科学,2010, 28(4):549-554.

[19］张丽丽,殷峻暹,蒋云钟等. 鄱阳湖自然保护区湿地植被群落与水文情势关系. 水科学进展, 2012, 23(6):769-776.

[20］梁守真,邢前国,施 平等. 山东省典型地表覆被 NDVI 时间序列谐波分析. 生态学杂志,2011,30(1):59-65.

[21] 李加林. 基于 MODIS 的沿海带状植被 NDVI/EVI 季节变化研究一一以江苏沿海互花米草盐沼为例. 海洋通报, $2006,25(6): 91-96$.

[22] 叶 春,赵晓松, 吴桂平等. 鄱阳湖自然保护区植被生物量时空变化及水位影响. 湖泊科学, 2013, 25 (5): 707-714.

[23] 冯 妍,何涁方, 唐怀瓯等. 安徽省 2000-2009 年不同类型植被的变化及其与气温, 降水的关系. 生态学杂志, 2012,31 (11) :2926-2934.

[24] 郑有飞,牛鲁燕,吴荣军等. $1982-2003$ 年贵州省植被覆盖变化及其对气候变化的响应. 生态学杂志, 2009, 28 (9) :1773-1778. 